\title{
BMJ Open Is education or income associated with insufficient fruit and vegetable intake among cancer survivors? A cross- sectional analysis of 2017 BRFSS data
}

\author{
Zhikai Zhu (D) ,1,2 Dongyu Zhang (D) , ${ }^{2}$ Judy Huei-yu Wang, ${ }^{2}$ Youlin Qiao, ${ }^{3}$ \\ Yuanli Liu, ${ }^{1}$ Dejana Braithwaite ${ }^{4,5,6}$
}

To cite: Zhu Z, Zhang D, Wang $\mathrm{JH}$, et al. Is education or income associated with insufficient fruit and vegetable intake among cancer survivors? A cross-sectional analysis of 2017 BRFSS data. BMJ Open 2020;10:e041285. doi:10.1136/ bmjopen-2020-041285

- Prepublication history and additional material for this paper is available online. To view these files, please visit the journal online (http://dx.doi.org/10. 1136/bmjopen-2020-041285).

Received 04 June 2020 Revised 10 November 2020 Accepted 11 November 2020

Check for updates

(C) Author(s) (or their employer(s)) 2020. Re-use permitted under CC BY-NC. No commercial re-use. See rights and permissions. Published by BMJ.

For numbered affiliations see end of article.

Correspondence to Dr Dongyu Zhang; dz216@georgetown.edu and

Professor Yuanli Liu;

liuyuanli_pumc@163.com

\section{ABSTRACT}

Objectives Previous studies found that low education or income level was associated with insufficient fruit and vegetable consumption (IFVC) among the general population. However, cancer survivors can be heterogeneous from the general population in many aspects. Our objective was to disentangle their association among cancer survivors.

Design Nationwide cross-sectional survey in the USA. Setting 2017 Behaviour Risk Factor Surveillance System. Participants 5409 cancer survivors.

Exposure and outcome Educational level (graduated from college/technical school, attended college/technical school and high school or less) and annual household income ( $\geq$ US\$75 000, US\$35 000 to <US\$75 000 and $<$ US\$35 000) were exposures of interest. IFVC, which was defined as $<5$ servings/day according to the American Cancer Society recommendation, was treated as the outcome.

Data analysis Multivariable logistic regression corrected for sampling weight was performed to estimate the association. Subgroup analyses and interaction tests were performed by age, gender, obesity and physical activity. Results Overall, 4750 survivors (weighted percentage: $88.5 \%$ ) had IFVC. Participants with lower education had a significantly higher rate of IFVC (high school or less vs college graduates: adjusted $\mathrm{OR}=2.17,95 \% \mathrm{Cl} 1.45$ to 3.25 , $p$ trend $<0.01$ ). The association between income and IFVC was almost null. Associations did not differ in most subgroups; however, the association of lower education appeared to be more substantial among physically inactive survivors ( $p$ interaction $<0.01$ ).

Conclusion Low educational background, not low income, was associated with IFVC among cancer survivors. Prospective cohort studies are needed to verify the conclusion.

\section{INTRODUCTION}

Several decades ago, cancer was a refractory disease due to the lack of accurate detection methods and effective antitumour medication. However, improvements in medical techniques and clinical treatment modalities have allowed a great proportion of patients with cancer to survive for longer periods of
Strengths and limitations of this study

- The large sample size in Behavioural Risk Factor Surveillance System (BRFSS) ensures a good power and reduces imprecision.

- Subgroup analysis helps us verify whether the impact of education is stronger in certain groups, like physically inactive survivors.

- Cancer diagnosis was measured by self-report, which is less valid compared with medical record review.

- BRFSS measured fruit and vegetable consumption during the past 1 month, which might not be sufficient to reflect participants' long-term or constant intake level.

time after diagnosis. ${ }^{1}$ To date, the number of cancer survivors continues to increase and now accounts for about $5 \%$ of the US population. ${ }^{2}$ More than 16.9 million people in the USA have personal histories of cancer in 2019 and this number is estimated to reach 22.1 million by $2030 .{ }^{1}$ This trajectory underscores the importance of tertiary prevention in cancer survivors, which can help survivors maintain general health and promote quality of life.

A diet with sufficient fruit and vegetable can be beneficial to cancer survivors, which is critical in tertiary prevention. ${ }^{3}$ Fruit and vegetable contain a myriad of nutrients and phytochemicals, including fibre, vitamins, antioxidants, potassium, flavonoids and other compounds ${ }^{4}$ that potentially inhibit cancer progression $^{5}$ and reduce mortality. ${ }^{6} 7$ Epidemiological studies have shown that a diet with sufficient fruit and vegetable was associated with a lower mortality in breast ${ }^{6}$ and colon cancer survivors ${ }^{7}$ as well as better quality of life. ${ }^{8}$ The American Cancer Society (ACS) suggests that cancer survivors should consume at least five servings of fruit and vegetable per 
day. ${ }^{9}$ However, previous research shows that only a small fraction $(15 \%-20 \%)$ of survivors have sufficient fruit and vegetable intake. ${ }^{10}$

Previous studies found that unfavourable education or income level was associated with insufficient fruit and vegetable consumption (IFVC) among the general population. ${ }^{11}$ A systematic review focusing on low-income and middle-income countries found that high socioeconomic status (measured through education, income or composite indicators) was associated with higher fruit and/or vegetable consumption, diet quality and food diversity. ${ }^{12}$ However, cancer survivors can be heterogeneous from the general population in many aspects. For example, due to high medical expenditure, many survivors experience economic hardship, ${ }^{13}$ which may affect their fruit and vegetable purchase. Survivors with higher education are more likely to change their dietary habits ${ }^{14}$ when being informed of cancer diagnosis. Such evidence suggests that the association pattern of education or income among cancer survivors may differ from that of the general population. Given the limited evidence regarding associations between educational background and income and fruit and vegetable consumption among cancer survivors, we used the 2017 Behavioural Risk Factor Surveillance System (BRFSS) data to disentangle these relationships.

\section{METHODS}

\section{BRFSS and study population}

BRFSS is an annual cross-sectional telephone survey conducted in the USA since 1984 by the Centres for Disease Control and Prevention. The survey collects data from adult US residents ( $\geq 18$ years) regarding their health-related risk behaviours, chronic health conditions and use of preventive services. Survey questions went through technical review, cognitive testing and field testing before being placed on the questionnaire. The BRFSS collects information from all 50 states, the District of Columbia, Puerto Rico, the US Virgin Islands, Guam, American Samoa and Palau. Detailed information about BRFSS can be found at www.cdc.gov/brfss/about/ index.htm. For our current study, a total of 5409 cancer survivors without missing data of exposure, outcome and other covariates were included for analysis. Specifically, we treated cancer survivors as people self-reporting histories of cancer diagnosis based on definitions from the National Coalition for Cancer Survivorship. ${ }^{15}$

\section{Patient and public involvement}

Survey respondents were selected as described above and were not involved in the design of this study.

\section{Measures}

The 2017 BRFSS asked four questions to assess how many servings of fruit and vegetable participants consumed per day during the past month, which included intake of the following items: (1) fruit (non-juice), (2) dark green vegetable, (3) potato (not including fries or fried potato) and (4) other types of vegetable. We defined IFVC as $<5$ servings/day. ${ }^{16} 17$

Educational background and annual household income were exposures of interest in the analysis. Participants self-reported the highest grade or year of school completed as well as the annual household income from all sources in the BRFSS. We categorised education and income as the following ordinal variables to ensure each level had sufficient and similar number of observations: (1) education: graduated from college/technical school, attended college/technical school and high school or less and (2) income: $\geq \mathrm{US} \$ 75000$, US\$35 000 to $<\mathrm{US} \$ 75000$ and $<$ US\$35 000 .

Demographic characteristics included age, gender, race and marital status. We treated age as an ordinal variable $(<65,65-74$ and $\geq 75$ years $)$ to approximate tertiles. We categorised race as white, black and other. We reclassified self-reported marital status as married (married couple or member of an unmarried couple) and not married (never married, divorced, widowed or separated) because being unmarried could be associated with a significant decrease in quantity and variety of fruit and vegetable intake. ${ }^{18}$ Health-related lifestyle indicators, which included smoking, alcohol drinking, obesity and physical activity, were included for analysis since they were closely associated with our exposures of interest and dietary behaviours. ${ }^{19}$ We categorised smoking status as never smoked, current smoker or former smoker. We defined heavy alcohol drinking as consuming $\geq 14$ drinks / week for male respondents or $\geq 7$ drinks/week for female respondents. ${ }^{20}$ Obesity was defined as having a body mass index $\geq 30 \mathrm{~kg} / \mathrm{m}^{2}$. Physical inactivity was defined as having no physical activity or exercise (eg, running, callisthenics, golf, gardening or walking) during the past month. ${ }^{21}$ The BRFSS treated respondents' general health as a binary variable (fair or poor vs good, very good or excellent). ${ }^{22}$ Major comorbidities, including diabetes mellitus, high blood cholesterol, high blood pressure, myocardial infarction, coronary heart disease, stroke, chronic kidney disease, arthritis, asthma, chronic obstructive pulmonary disease and depressive disorder, were also measured via self-report. Participants' self-reported histories of routine clinical check-ups and healthcare coverage that included health insurance, prepaid plans (eg, Health Maintenance Organization), government plans (eg, Medicare) and Indian Health Service. ${ }^{23}$ Cancer-related indicators included time elapsed since cancer diagnosis, number of cancers diagnosed and cancer type.

All sociodemographic and health-related factors were selected based on previously published articles and a priori knowledge regarding the associations between these factors and our exposures of interest and IFVC.

\section{Statistical analysis}

As this is a complete-case analysis, no statistical method was used to handle missing data. The 2017 BRFSS used iterative proportional fitting to weight data. This allowed 
incorporation of telephone survey data and introduction of more demographic characteristics, which better reflected the sociodemographic distribution of each individual state. We used number of observations and weighted percentages $(\%)$ of covariates to descriptively summarise the overall sample and subpopulation defined by IFVC, and we used $\chi^{2}$ tests to compare distributions of these covariates by IFVC. When summarising education and income, we reported number of observations for each level and calculated weighted point estimates and 95\% CIs of IFVC prevalence. We used logistic regression corrected for sampling weight to estimate ORs and 95\% CIs of education and income. In crude models, only one independent variable (education or income) was included. In multivariable logistic regression, we included education and income simultaneously and adjusted for age, gender, race, marital status, smoking status, alcohol drinking, physical activity, obesity, general health, number of comorbidities, healthcare coverage, clinical check-up, comorbidity, time elapsed since cancer diagnosis and number of cancers. We conducted tests for trends by treating education and income as continuous variables in the model. Based on parameters in the multivariable model, we used 'margins' in Stata with unconditional variance-covariance matrix to calculate model-adjusted probability of IFVC by education levels within each stratum of income (or by income levels within each education stratum). Two sets of sensitivity analyses were conducted in addition to the primary logistic regression models. Specifically, the sensitivity analysis was restricted to survivors who only had one cancer $(n=4284)$ or survived for more than 1 year $(\mathrm{n}=4699)$ to preclude the impact from antitumour treatment that might affect dietary behaviours. To verify the robustness of primary analysis, we used a linear regression model treating fruit and vegetable consumption as a continuous variable to calculate the mean difference for education and income; the model adjusted for the same set of covariates.

Several factors, including age ( $<65$ vs $\geq 65$ years), gender (female vs male) and health-related factors, could substantially affect people's dietary pattern. ${ }^{24-27}$ Thus, we conducted subgroup analyses stratified by these variables to explore if there were interactions between education and income and these factors in relation to IFVC. We chose obesity and physical inactivity as the indicators of adverse lifestyle factors; smoking and heavy alcohol drinking were not considered due to the uneven distribution within the variable. We added interaction terms between education and income and age, gender, obesity and physical inactivity into the model and used Wald tests to examine whether there was a significant interaction. In addition, we estimated adjusted OR (aOR) and model-adjusted probability of IFVC for breast and prostate cancer and melanoma because they had large sample sizes compared with other types of cancer and their favourable survival endowed more opportunities for tertiary prevention.

For current analysis, two-sided $\mathrm{p}$ values $<0.05$ were considered to be statistically significant. All statistical analyses were conducted using Stata, V.15.0 (College Station, Texas, USA: StataCorp, LLP).

\section{RESULTS}

Table 1 descriptively summarises demographic characteristics and health-related factors of the overall sample. Among the 5409 cancer survivors, 4750 (weighted percentage: $88.5 \%$ ) had IFVC. Overall, most of the participants were aged $\geq 65(64.5 \%)$ years and the mean age was 66.9 (SD: 11.0) years. Over half of the survivors were women $(57.2 \%)$ and the majority of survivors was white $(94.1 \%)$. Over one-third of study participants were unmarried (39.4\%). In terms of lifestyle behaviours, approximately half of the survivors were never-smokers $(52.0 \%)$, most survivors were not heavy drinkers $(95.4 \%)$ and $28.1 \%$ of survivors were physically inactive during the past month. Prevalence of obesity was $34.7 \%$ and about a quarter $(25.7 \%)$ of survivors were living with poor or fair general health. By pooling all types of comorbidities, the data showed only $11.3 \%$ had no comorbidity, while $18.6 \%$ had one comorbidity and $70.1 \%$ had at least two comorbidities. Most survivors (84.6\%) reported that they had a clinical check-up last year and $97.4 \%$ had healthcare coverage. Overall, about half $(51.5 \%)$ of the survivors had cancer diagnoses within the recent 10 years and $79.2 \%$ of them had only one cancer. In aspects of cancer type, the prevalence of female breast cancer, prostate cancer, gastrointestinal cancer and melanoma was $15.5 \%, 10.1 \%$, $5.1 \%$ and $13.2 \%$, respectively. Pearson's $\chi^{2}$ tests indicated that survivors who were men, not married, current smoker, physically inactive, obese, self-reporting a favourable general health or living with $\geq 2$ comorbidities were more likely to have IFVC $(\mathrm{ps}<0.05)$.

Educational level and household income were evenly distributed and two-sample proportion tests showed that the weighted prevalence of IFVC increased with the decline of educational level and household income. Overall, participants with an education background at or lower than high school, as compared with those graduating from college or technical school, had a significantly higher rate of IFVC (crude OR (cOR) $=2.76,95 \%$ CI 1.91 to 3.98 ; aOR=2.17, $95 \%$ CI 1.45 to 3.25 ) in both crude and multivariable models; the statistical test suggested a significant trend ( $p$ trend $<0.01$ ). Although the crude model showed a significant association between household income and IFVC ( $<$ US $\$ 35000$ vs $\geq$ US $\$ 75$ 000/year: cOR $=2.00,95 \%$ CI 1.38 to 2.89 , $p$ trend $<0.01)$, the effect measure turned null in the multivariable analysis $(<\mathrm{US} \$ 35$ 000 vs $\geq$ US $\$ 75000$ /year: aOR $=1.02,95 \%$ CI 0.65 to 1.62 , $\mathrm{p}$ trend $=0.90$ ) (table 2). Effect measures of other covariates are presented in online supplemental table 1. Association patterns of education and income among survivors with only one cancer and survivors living for more than 1 year after cancer diagnosis were largely similar to estimates obtained in the primary analysis (table 2). By treating fruit and vegetable servings as the outcome in multivariable linear regression, the model suggested that 
Table 1 Characteristics of 5409 cancer survivors from 2017 BRFSS

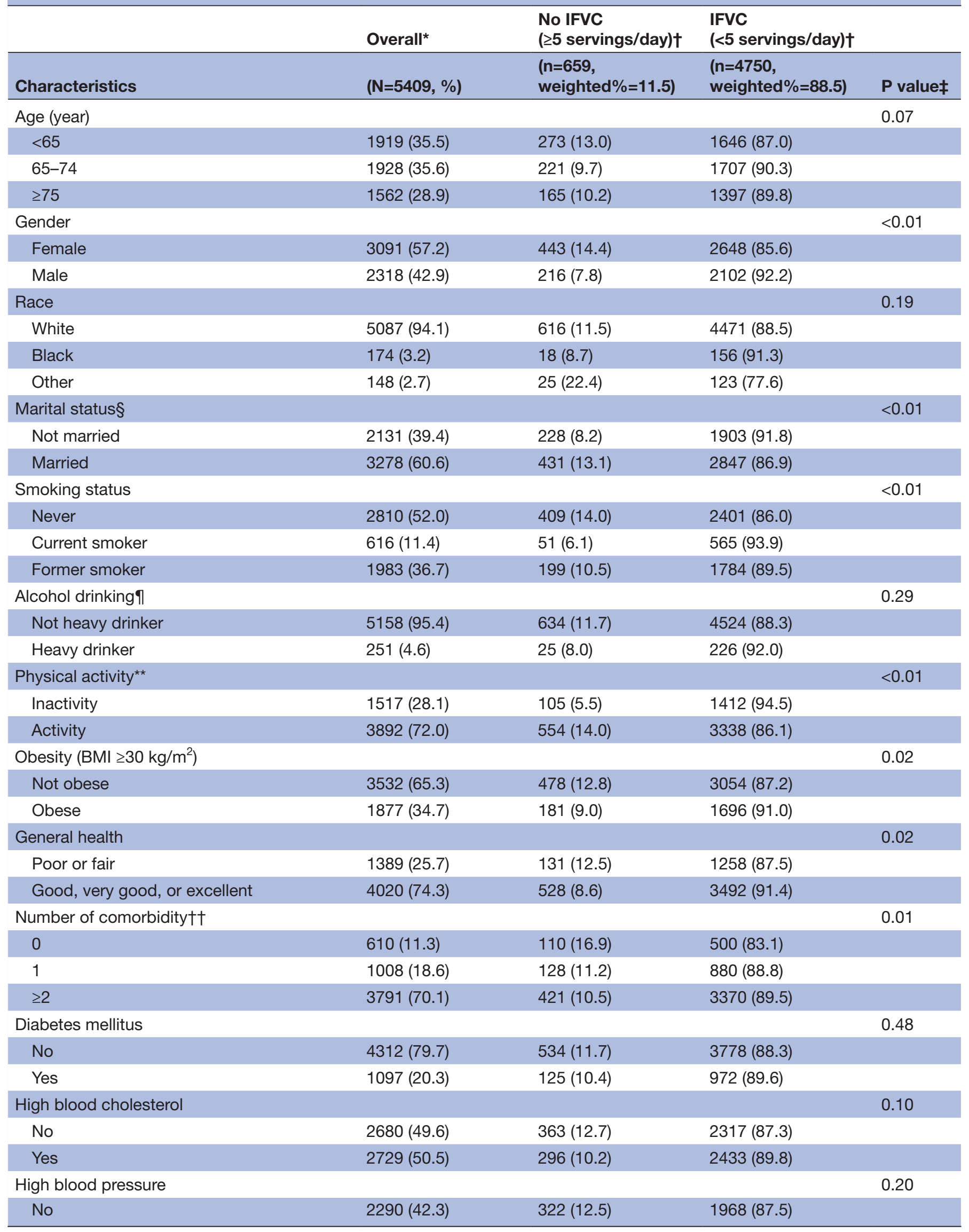


Table 1 Continued

\begin{tabular}{|c|c|c|c|c|}
\hline & Overall* & $\begin{array}{l}\text { No IFVC } \\
\text { ( } \geq 5 \text { servings/day) } \dagger\end{array}$ & $\begin{array}{l}\text { IFVC } \\
\text { (<5 servings/day) } \dagger\end{array}$ & \\
\hline Characteristics & $(\mathrm{N}=5409, \%)$ & $\begin{array}{l}(n=659, \\
\text { weighted } \%=11.5)\end{array}$ & $\begin{array}{l}(n=4750, \\
\text { weighted } \%=88.5)\end{array}$ & P value \\
\hline Yes & $3119(57.7)$ & $337(10.6)$ & $2782(89.4)$ & \\
\hline Myocardial infarction & & & & 0.41 \\
\hline Coronary heart disease & & & & 0.32 \\
\hline No & $4816(89.0)$ & $591(11.2)$ & 4225 (88.9) & \\
\hline Yes & $593(11.0)$ & $68(13.8)$ & $525(86.2)$ & \\
\hline Stroke & & & & 0.72 \\
\hline No & $4981(92.1)$ & $610(11.7)$ & $4371(88.3)$ & \\
\hline Yes & $428(7.9)$ & $49(9.4)$ & $379(90.6)$ & \\
\hline Arthritis & & & & 0.02 \\
\hline No & $2631(48.6)$ & 355 (13.2) & $2276(86.8)$ & \\
\hline Yes & $2778(51.4)$ & $304(9.8)$ & 2474 (90.2) & \\
\hline Asthma & & & & 0.37 \\
\hline No & $4621(85.4)$ & $558(11.8)$ & 4063 (88.3) & \\
\hline Yes & $788(14.6)$ & $101(10.0)$ & $687(90.0)$ & \\
\hline Had clinical check-up last year & & & & 0.29 \\
\hline Had no check-up & $831(15.4)$ & $94(9.6)$ & $737(90.4)$ & \\
\hline Had check-up & 4578 (84.6) & $565(11.8)$ & 4013 (88.2) & \\
\hline Had healthcare coverage & & & & 0.98 \\
\hline Had no coverage & $143(2.6)$ & $17(11.4)$ & $126(88.6)$ & \\
\hline Had coverage & $5266(97.4)$ & $642(11.5)$ & $4624(88.5)$ & \\
\hline Survival time (year) & & & & 0.65 \\
\hline $0-4$ & $1679(31.0)$ & $202(12.4)$ & 1477 (87.6) & \\
\hline $5-9$ & $1105(20.4)$ & $127(10.7)$ & 978 (89.3) & \\
\hline$\geq 10$ & 2625 (48.5) & $330(11.1)$ & 2295 (88.9) & \\
\hline Number of cancer & & & & 0.90 \\
\hline 1 & 4284 (79.2) & 509 (11.5) & 3775 (88.5) & \\
\hline$\geq 2$ & 1125 (20.8) & $150(11.3)$ & $975(88.7)$ & \\
\hline Cancer types & & & & $<0.01$ \\
\hline Breast (only female) & $836(15.5)$ & $122(18.6)$ & $714(81.4)$ & \\
\hline Prostate & $544(10.1)$ & $41(5.8)$ & $503(94.2)$ & \\
\hline Gastrointestinalł‡ & $273(5.1)$ & $26(7.0)$ & $247(93.0)$ & \\
\hline
\end{tabular}




\begin{tabular}{|c|c|c|c|c|}
\hline & Overall* & $\begin{array}{l}\text { No IFVC } \\
\text { ( } \geq 5 \text { servings/day) } \dagger\end{array}$ & $\begin{array}{l}\text { IFVC } \\
\text { (<5 servings/day) } †\end{array}$ & \\
\hline Characteristics & $(\mathrm{N}=5409, \%)$ & $\begin{array}{l}(n=659, \\
\text { weighted } \%=11.5)\end{array}$ & $\begin{array}{l}(n=4750, \\
\text { weighted\%=88.5) }\end{array}$ & P value $\neq$ \\
\hline Melanoma & 715 (13.2) & 83 (12.6) & $632(87.4)$ & \\
\hline Other & 3041 (56.2) & 387 (10.9) & 2654 (89.2) & \\
\hline
\end{tabular}

Note: Number of observations and weight percentages (\%) were reported for study characteristics. Boldface indicates statistical significance $(\mathrm{p}<0.05)$.

${ }^{*}$ Column percentage was reported for the overall sample.

†Row percentage was reported for subpopulation defined by IFVC.

$\ddagger \chi^{2}$ test was used to compare distributions of variables differed by IFVC.

$\S$ Not married was defined as never married, divorced, widowed, or separated. Respondents who were a member of a married or unmarried couple were defined as married.

१Men having more than 14 drinks per week and women having more than 7 drinks per week were considered as heavy drinkers.

${ }^{\star *}$ People who did not participate in any physical activities or exercises (eg, running, callisthenics, golf, gardening, or walking for exercise) in addition during the past month were considered as inactivity.

††Comorbidities were diabetes mellitus, high blood cholesterol, high blood pressure, myocardial infarction, coronary heart disease, stroke, chronic kidney disease, arthritis, asthma, COPD and depressive disorder.

$\ddagger$ Gastrointestinal cancer included oesophageal cancer, gastric cancer, and colorectal cancer.

BMI, body mass index; BRFSS, behavioural risk factor surveillance system; COPD, chronic obstructive pulmonary disease; IFVC, insufficient fruit and vegetable consumption.

lower educational level was significantly associated with an increased fruit and vegetable consumption; effect measures of income were non-significant in linear regression (see online supplemental table 2).

Results of model-adjusted probability (figure 1A, B) showed the same association patterns as the primary analysis. Specifically, probability of IFVC was very similar across different levels of income regardless of educational attainment; in each stratum of income, the probability of IFVC increased as educational level decreased. Detailed estimates are included in online supplemental table 3.

The association of IFVC with education and income did not differ in subgroups defined by age, gender and obesity (table 3 ). The aORs of educational levels among each age group were similar to those in primary multivariable analysis $(p$ interaction $=0.83, p$ trend $<0.01$ for age $<65$ years, $p$ trend $=0.01$ for age $\geq 65$ years). Although point estimates of aORs of lower income $(<$ US\$35 000) were in different directions by age groups, the Wald test did not support a significant interaction either ( $\mathrm{p}$ interaction $=0.08$ ). There was no evidence suggesting a significant interaction between education/income and gender in relation to IFVC ( $p$ interaction $=0.20$ for education, $p$ interaction $=0.75$ for income). There was no significant interaction between obesity and education/income in relation to IFVC ( $\mathrm{p}$ interaction $=0.42$ for education, $\mathrm{p}$ interaction $=0.20$ for income). However, results (table 3 ) showed that the impact of lower educational level was more substantial among survivors with inactive lifestyle (high school or less vs graduated from college/technical school: aOR=6.21, 95\% CI 2.98 to 12.93 , p interaction $<0.01$ ); no significant interaction was observed between inactivity and income ( $\mathrm{p}$ interaction $=0.07$ ).

A positive association between low education (high school or less vs graduated from college) and IFVC was observed for breast cancer $(\mathrm{aOR}=2.73,95 \%$ CI 1.52 to 4.88 , $\mathrm{p}$ trend $<0.01)$ and melanoma $(\mathrm{aOR}=1.92,95 \%$ CI 0.98 to 3.77 , p trend=0.04), although statistical significance was not observed for the latter; effect measures of education among prostate cancer survivors were not significant. There were no significant associations between income and IFVC for breast and prostate cancer and melanoma (see online supplemental table 4). Modeladjusted probability of IFVC among survivors of breast and prostate cancer and melanoma is presented in online supplemental table 5 .

\section{DISCUSSION}

In general, we found that a high rate $(88.5 \%)$ of participants did not adhere to the ACS recommended five servings of fruit and vegetable per day. Low-level education was found to be positively associated with IFVC. While low-level household income was also positively associated with IFVC in unadjusted logistic regression, the relationship was not significant in the multivariable logistic regression. The association patterns were largely unchanged among cancer survivors with only one cancer or surviving for more than 1 year since diagnosis. The impact of lower education on IFVC appeared to be more substantial among physically inactive survivors, whereas there was no significant interaction between age, gender or obesity and education in relation to IFVC. No interaction was observed for income.

The findings on educational level are in line with conclusions from previous population-based research, but the results on income are not consistent. Mayer et $a l$ investigated 619 cancer survivors using a nationwide survey in the USA during 2002-2003 and reported that survivors with an education background lower than high 
Table 2 Associations of IFVC with education and income among cancer survivors in the USA

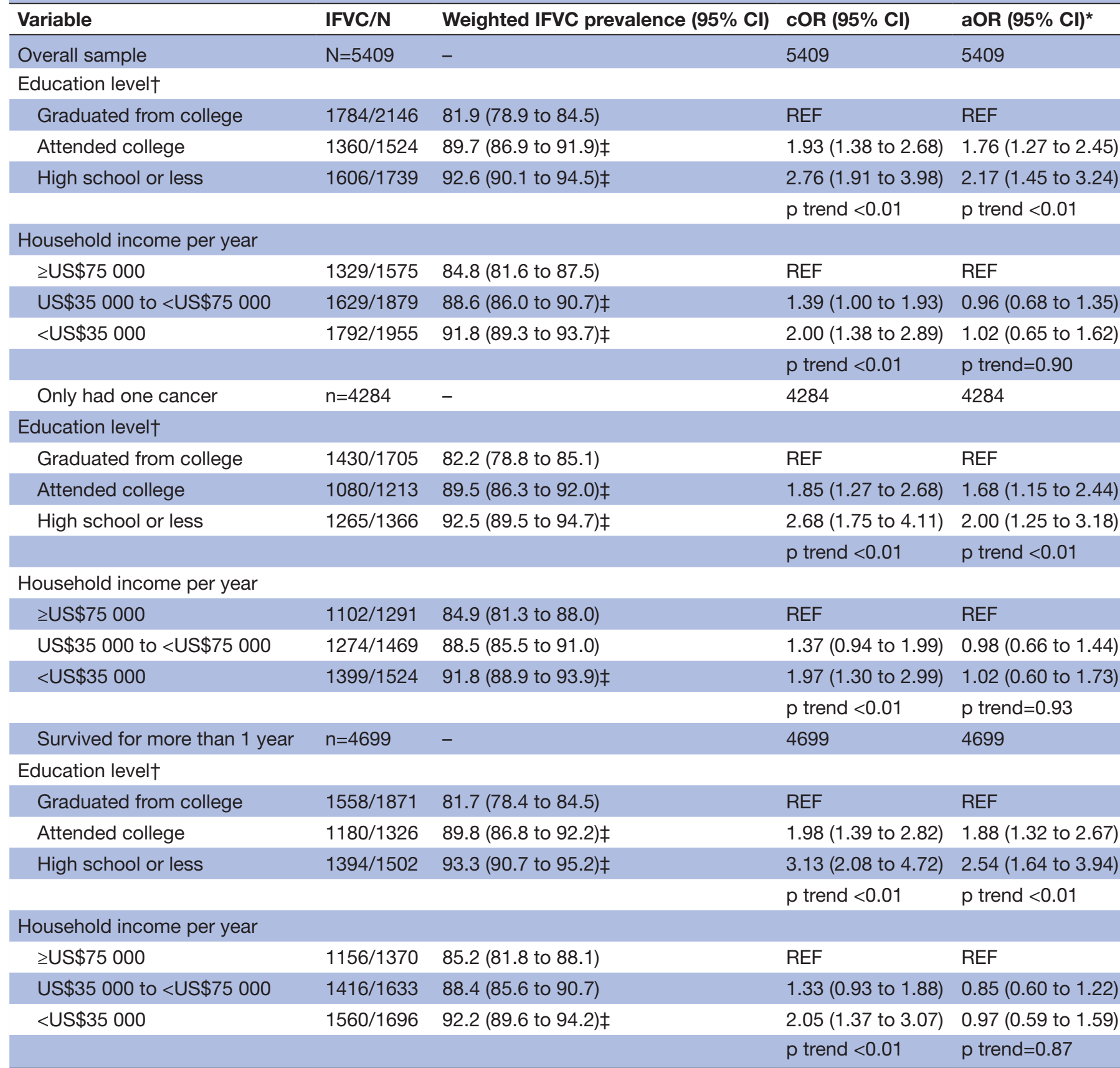

Note: OR and $95 \% \mathrm{Cl}$ were calculated from logistic regression corrected for sampling weight in BRFSS.

*The multivariable model included education and income simultaneously and adjusted for age, gender, race, marital status, smoking status, alcohol drinking, physical activity, obesity, general health, healthcare coverage, clinical check-up, comorbidity, survival time, and number of cancer.

†College-level education also included technical school.

‡Two-sample proportion test indicated a significant difference from reference group in aspects of IFVC.

aOR, adjusted OR; BRFSS, Behavioural Risk Factor Surveillance System; cOR, crude OR; IFVC, insufficient fruit and vegetable consumption.

school were less likely to eat at least five servings of fruit or vegetable per day (OR=0.6, $95 \%$ CI 0.4 to 0.8$).{ }^{28}$ Given the potential secular variation, cancer survivors of the current era may have different dietary patterns or health awareness compared with survivors studied 15 years ago, suggesting the conclusions need further verification using a more recent data. Another population-based study in the USA analysed 2865 breast cancer survivors and found that, when compared with their peers with education at or less than high school, women who had graduated from college were more likely to have a substantial increase in fruit and vegetable consumption after cancer diagnosis, although the association patterns of income were largely non-significant. ${ }^{29}$ However, it did not disentangle whether 

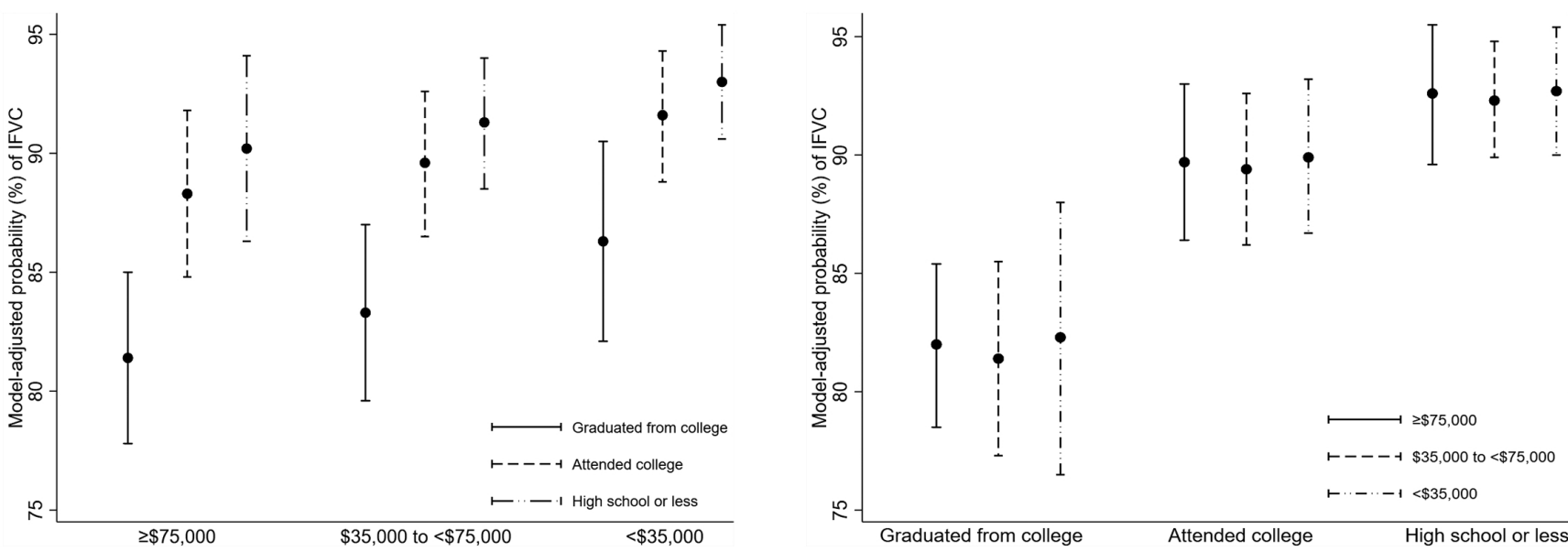

survivors with favourable educational background or income level were more likely to meet the recommended dietary requirement. A prospective study measured average fruit and vegetable intake of 2134 prostate cancer survivors during 2004-2005 and reported positive associations of consumption level with education and income; however, this outcome was based on a $\chi^{2}$ test and could be biassed due to confounders. ${ }^{30}$ These issues were carefully considered and addressed in current analysis by using the recent nationwide survey data.

We have some speculations about mechanisms behind the association patterns in our analysis. First, several studies show that education can improve survivors' health awareness. Advanced education can help survivors better understand health benefits of eating sufficient fruit and vegetable like progression risk reduction and improvement in survival ${ }^{3031}$; this may finally reduce their likelihood of low-level intake. ${ }^{32}{ }^{33}$ Second, education decreases worry and fear of cancer harm (eg, shorter life expectancy, recurrence and lower life quality), ${ }^{34}$ which can be barriers to healthy dietary behaviours. ${ }^{35}$ For example, Skaali et $a l^{34}$ showed that medium-level education (11-12 years), as compared with high-level education ( $\geq 13$ years), was significantly associated with a higher fear of recurrence score among 1336 long-term testicular cancer survivors $(\mathrm{OR}=1.51,95 \%$ CI 1.18 to 1.93$)$ in Norway. Third, we speculate that educational level can be the key confounder between income and IFVC because the effect measures of income became null when education and income were included in the multivariable model simultaneously and the a priori knowledge suggested income could be a surrogate or downstream event of educational attainment. ${ }^{36}$ This may imply that individuals' food intakes are influenced more by their educational attainment than the adequacy of their household incomes. Finally, physical inactivity is an indicator of adverse lifestyle behaviour and it may have synergistic effects with poor health awareness conferred by low education, ${ }^{37} 38$ which partially explains why the effect measures of low-level education are more substantial among inactive survivors.

The current study has several strengths in design and analysis. To our knowledge, this is the first study to use BRFSS data to characterise associations between education and income and IFVC among cancer survivors; the large sample size in BRFSS ensures a good power for statistical analysis and reduces imprecision. Second, the weighted analysis reduces impact of selection bias and multiple sets of sensitivity analyses further validate robustness of the association identified in the primary analysis. Additionally, potential effect modification by several covariates has been investigated in subgroup analyses and can help us verify if the impact of education or income is stronger in certain groups, allowing researchers to establish a more targeted health intervention programme. However, several limitations should be considered when interpreting the results. First, cancer diagnosis and other illnesses were all measured by self-report, which can be less valid compared with medical record review. Second, the BRFSS lacks discrimination among the categories of fruit and vegetable intake, and it only measured fruit and vegetable consumption during the past 1 month, which might not be sufficient to reflect participants' long-term or constant intake level. Besides, we could not ascertain whether the current dietary behaviour represents an improvement when compared with dietary behaviour before cancer diagnosis. The high prevalence of IFVC among cancer survivors may mask the insufficient attempt to enhance the dietary behaviour. Third, survivors of gastrointestinal cancer are more likely to be affected in aspects of dietary behaviours due to clinical characteristics and treatments of the tumour, ${ }^{39}$ whereas numbers of survivors of oesophageal, gastric and colorectal cancer are very limited in the BRFSS data set, making the conclusion less generalisable to these survivors. Finally, the 2017 BRFSS is a cross-sectional study and causal relationship between exposures and outcome cannot be investigated. 


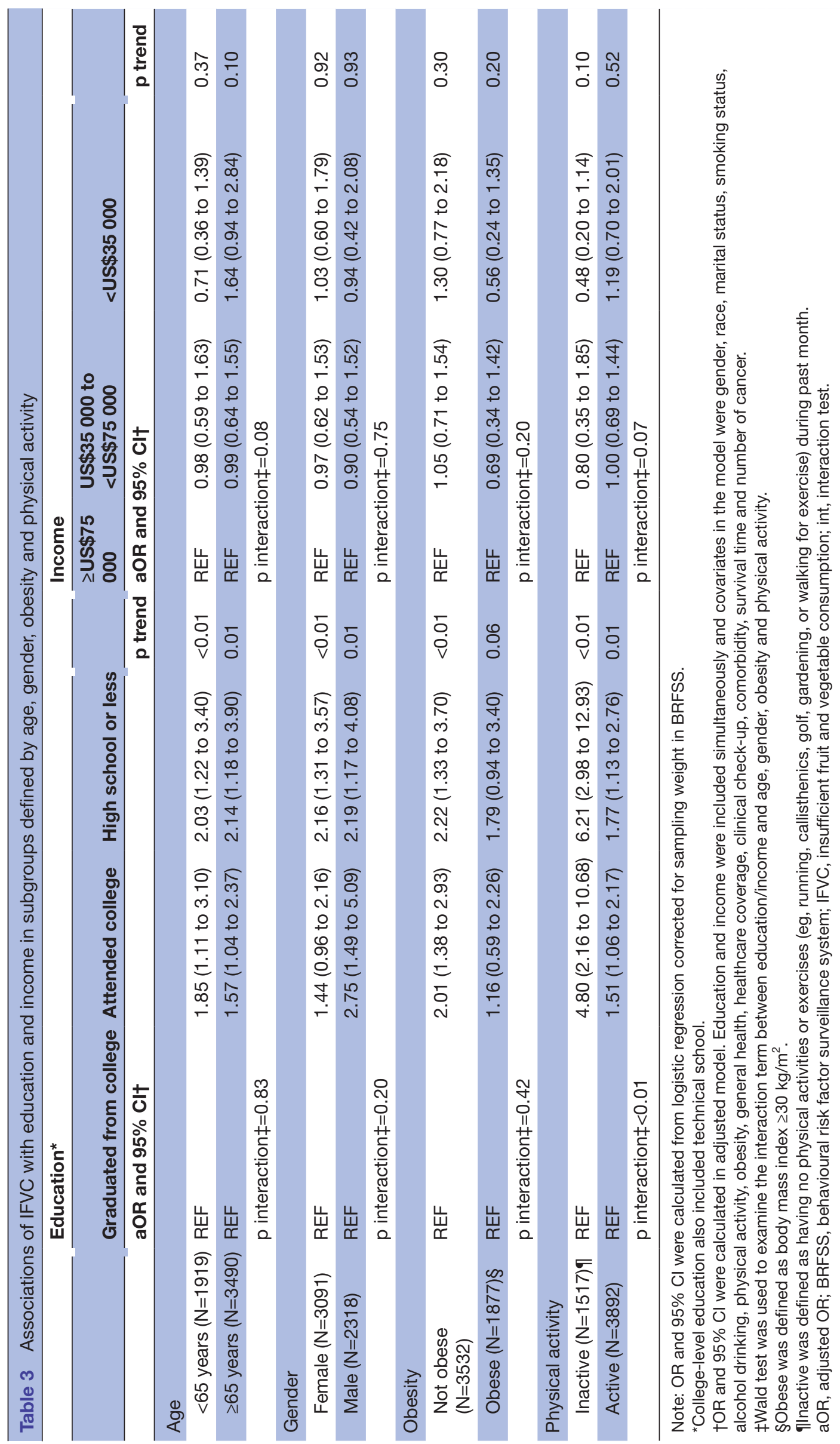


Our study provides several health implications. Particularly, the results suggest that education plays a key role in survivors' adherence to the ACS recommendation of five servings of fruit and vegetable each day and increasing survivors' health awareness and knowledge can be fundamental in dietary intervention. While educational attainment can hardly be modifiable, diet-related health education is viable as shown in several knowledge-based dietary intervention programmes, ${ }^{40}$ especially for cancer survivors with low education background. In conclusion, this research suggests that low education background, but not low income, maybe a barrier to fruit and vegetable consumption among cancer survivors. Such effects may differ by negative lifestyle factors like physical inactivity, but this needs further verification in studies with more comprehensive measures of lifestyle behaviours. Future studies with a comprehensive measure of dietary intake (eg, the category and amount) will be needed to verify the conclusions in this study.

\section{Author affiliations}

${ }^{1}$ School of Health Policy and Management, Chinese Academy of Medical Sciences \& Peking Union Medical College, Beijing, China

${ }^{2}$ Department of Oncology, Georgetown University School of Medicine, Washington, District of Columbia, USA

${ }^{3}$ Department of Cancer Epidemiology, National Cancer Center/National Clinical Research Center for Cancer/Cancer Hospital, Chinese Academy of Medical Sciences \& Peking Union Medical College, Beijing, China

${ }^{4}$ University of Florida Health Cancer Center, Gainesville, Florida, USA

${ }^{5}$ Department of Epidemiology, College of Public Health and Health Professions, University of Florida, Gainesville, Florida, USA

${ }^{6}$ Department of Aging and Geriatric Research, College of Medicine, University of Florida, Gainesville, Florida, USA

Acknowledgements We thank Anthony Chicaiza of the Georgetown University Lombardi Comprehensive Cancer Center for language editing and proofreading. The authors appreciate research staff participating in BRFSS data collection, management and dissemination.

Contributors All of the authors contributed to this work. ZZ and DZ designed the study. ZZ and DZ conducted statistical analysis. ZZ and DZ drafted the manuscript. $\mathrm{ZZ}, \mathrm{DZ}, \mathrm{JH}-\mathrm{yW}, \mathrm{YQ}, \mathrm{YL}$ and DB participated in discussion and manuscript revision. All authors have approved the final version of the manuscript.

Funding This work was supported by Doctoral Student Innovation Fund, Peking Union Medical College PN: 2018-10001-06.

Competing interests None declared.

Patient consent for publication Not required.

Ethics approval We used publicly available deidentified data, which do not require IRB approval.

Provenance and peer review Not commissioned; externally peer reviewed.

Data availability statement Data are available in a public, open access repository.

Supplemental material This content has been supplied by the author(s). It has not been vetted by BMJ Publishing Group Limited (BMJ) and may not have been peer-reviewed. Any opinions or recommendations discussed are solely those of the author(s) and are not endorsed by BMJ. BMJ disclaims all liability and responsibility arising from any reliance placed on the content. Where the content includes any translated material, BMJ does not warrant the accuracy and reliability of the translations (including but not limited to local regulations, clinical guidelines, terminology, drug names and drug dosages), and is not responsible for any error and/or omissions arising from translation and adaptation or otherwise.

Open access This is an open access article distributed in accordance with the Creative Commons Attribution Non Commercial (CC BY-NC 4.0) license, which permits others to distribute, remix, adapt, build upon this work non-commercially, and license their derivative works on different terms, provided the original work is properly cited, appropriate credit is given, any changes made indicated, and the use is non-commercial. See: http://creativecommons.org/licenses/by-nc/4.0/.

ORCID iDs

Zhikai Zhu http://orcid.org/0000-0001-7623-2287

Dongyu Zhang http://orcid.org/0000-0002-3545-1771

\section{REFERENCES}

1 Miller KD, Nogueira L, Mariotto $A B$, et al. Cancer treatment and survivorship statistics, 2019. CA Cancer J Clin 2019;69:363-85.

2 Mayer DK, Nasso SF, Earp JA. Defining cancer survivors, their needs, and perspectives on survivorship health care in the USA. Lancet Oncol 2017;18:e11-18.

3 Zhang D, Feng Y, Li N, et al. Fruit and vegetable consumptions in relation to frequent mental distress in breast cancer survivors. Support Care Cancer 2020. doi:10.1007/s00520-020-05451-8. [Epub ahead of print: 26 Apr 2020].

4 Liu RH. Health-Promoting components of fruits and vegetables in the diet. Adv Nutr 2013;4:384S-92.

5 Rock CL, Doyle C, Demark-Wahnefried W, et al. Nutrition and physical activity guidelines for cancer survivors. CA Cancer J Clin 2012;62:242-74.

6 Kwan ML, Weltzien E, Kushi LH, et al. Dietary patterns and breast cancer recurrence and survival among women with early-stage breast cancer. J Clin Oncol 2009;27:919-26.

7 Van Blarigan EL, Fuchs CS, Niedzwiecki D, et al. Association of survival with adherence to the American cancer Society nutrition and physical activity guidelines for cancer survivors after colon cancer diagnosis: the CALGB 89803/Alliance trial. JAMA Oncol 2018;4:783-90.

8 Spector DJ, Noonan D, Mayer DK, et al. Are lifestyle behavioral factors associated with health-related quality of life in long-term survivors of non-Hodgkin lymphoma? Cancer 2015;121:3343-51.

9 Rock CL, Doyle C, Demark-Wahnefried W, et al. Nutrition and physical activity guidelines for cancer survivors. CA Cancer J Clin 2012;62:242-74.

10 Blanchard CM, Courneya KS, Stein K, et al. Cancer survivors' adherence to lifestyle behavior recommendations and associations with health-related quality of life: results from the American cancer Society's SCS-II. J Clin Oncol 2008;26:2198-204.

11 Giskes K, Avendano M, Brug J, et al. A systematic review of studies on socioeconomic inequalities in dietary intakes associated with weight gain and overweight/obesity conducted among European adults. Obes Rev 2010;11:413-29.

12 Mayén A-L, Marques-Vidal P, Paccaud F, et al. Socioeconomic determinants of dietary patterns in low- and middle-income countries: a systematic review. Am J Clin Nutr 2014;100:1520-31.

13 Guy GP, Yabroff KR, Ekwueme DU, et al. Economic burden of chronic conditions among survivors of cancer in the United States. J Clin Oncol 2017;35:2053-61.

14 Kostopoulou V, Katsouyanni K. The truth-telling issue and changes in lifestyle in patients with cancer. J Med Ethics 2006;32:693-7.

15 Khan NF, Rose PW, Evans J. Defining cancer survivorship: a more transparent approach is needed. J Cancer Surviv 2012;6:33-6.

16 Rooney C, McKinley MC, Appleton KM, et al. How much is '5-aday'? A qualitative investigation into consumer understanding of fruit and vegetable intake guidelines. J Hum Nutr Diet 2017;30:105-13.

17 Subar AF, Heimendinger J, Patterson BH, et al. Fruit and vegetable intake in the United States: the baseline survey of the five a day for better health program. Am J Health Promot 1995;9:352-60.

18 Vinther JL, Conklin Al, Wareham NJ, et al. Marital transitions and associated changes in fruit and vegetable intake: findings from the population-based prospective EPIC-Norfolk cohort, UK. Soc Sci Med 2016;157:120-6.

19 Allen L, Williams J, Townsend N, et al. Socioeconomic status and non-communicable disease behavioural risk factors in low-income and lower-middle-income countries: a systematic review. Lancet Glob Health 2017;5:e277-89.

20 Jiang N, Gonzalez M, Ling PM, et al. Smoke-free laws and hazardous drinking: a cross-sectional study among U.S. adults. Int J Environ Res Public Health 2017;14. doi:10.3390/ijerph14040412. [Epub ahead of print: 1304 2017].

21 Zhang D, Zhang C, Sun X, et al. BMI, physical inactivity, and Pap test use in Asian women in the U.S. Am J Prev Med 2019;56:e85-94 https://doi.org/

22 Cheruvu VK, Odhiambo LA, Mowls DS, et al. Health-Related quality of life in current smokers with COPD: factors associated with current 
smoking and new insights into sex differences. Int $J$ Chron Obstruct Pulmon Dis 2016;11:2211-9.

23 Zhang D, Advani S, Huchko M, et al. Impact of healthcare access and HIV testing on utilisation of cervical cancer screening among US women at high risk of HIV infection: cross-sectional analysis of 2016 BRFSS data. BMJ Open 2020;10:e031823.

$24 \mathrm{Xu} \mathrm{X,} \mathrm{Hall} \mathrm{J,} \mathrm{Byles} \mathrm{J,} \mathrm{et} \mathrm{al.} \mathrm{Dietary} \mathrm{pattern} \mathrm{is} \mathrm{associated} \mathrm{with} \mathrm{obesity}$ in older people in China: data from China health and nutrition survey (CHNS). Nutrients 2015;7:8170-88.

25 Kang Y, Kim J. Gender difference on the association between dietary patterns and metabolic syndrome in Korean population. Eur $\mathrm{J}$ Nutr 2016;55:2321-30.

26 Bibiloni MDM, Julibert A, Argelich E, et al. Western and Mediterranean dietary patterns and physical activity and fitness among Spanish older adults. Nutrients 2017;9. doi:10.3390/ nu9070704. [Epub ahead of print: 06 Jul 2017].

27 Wakimoto P, Block G. Dietary intake, dietary patterns, and changes with age: an epidemiological perspective. J Gerontol A Biol Sci Med Sci 2001;56 Spec No 2:65-80.

28 Mayer DK, Terrin NC, Menon U, et al. Health behaviors in cancer survivors. Oncol Nurs Forum 2007;34:643-51.

29 Shi Z, Rundle A, Genkinger JM, et al. Distinct trajectories of fruits and vegetables, dietary fat, and alcohol intake following a breast cancer diagnosis: the pathways study. Breast Cancer Res Treat 2020;179:229-40.

30 Richman EL, Carroll PR, Chan JM. Vegetable and fruit intake after diagnosis and risk of prostate cancer progression. Int $J$ Cancer 2012;131:201-10.

31 Pierce JP, Natarajan L, Caan BJ, et al. Influence of a diet very high in vegetables, fruit, and fiber and low in fat on prognosis following treatment for breast cancer: the women's healthy eating and living (WHEL) randomized trial. JAMA 2007;298:289-98.

32 Konttinen H, Sarlio-Lähteenkorva S, Silventoinen K, et al. SocioEconomic disparities in the consumption of vegetables, fruit and energy-dense foods: the role of motive priorities. Public Health Nutr 2013;16:873-82.

33 Cutler DM, Lleras-Muney A. Understanding differences in health behaviors by education. $J$ Health Econ 2010;29:1-28.

34 Skaali T, Fosså SD, Bremnes R, et al. Fear of recurrence in long-term testicular cancer survivors. Psychooncology 2009;18:580-8.

35 Williamson DA, White MA, York-Crowe E, et al. Cognitive-behavioral theories of eating disorders. Behav Modif 2004;28:711-38.

36 Bonaccio M, Di Castelnuovo A, Costanzo S, et al. Interaction between education and income on the risk of all-cause mortality: prospective results from the MOLI-SANI study. Int J Public Health 2016;61:765-76.

37 Waters EA, Hawkins E. Awareness of health outcomes associated with insufficient physical activity and associations with physical activity intentions and behavior. J Health Commun 2018;23:634-42.

38 Veluswamy SK, Maiya AG, Nair S, et al. Awareness of chronic disease related health benefits of physical activity among residents of a rural South Indian region: a cross-sectional study. Int J Behav Nutr Phys Act 2014:11:27.

39 Karimi P, Islami F, Anandasabapathy S, et al. Gastric cancer: descriptive epidemiology, risk factors, screening, and prevention. Cancer Epidemiol Biomarkers Prev 2014:23:700-13.

40 Greenlee H, Gaffney AO, Aycinena AC, et al. ¡Cocinar para SU Salud!: randomized controlled trial of a culturally based dietary intervention among Hispanic breast cancer survivors. J Acad Nutr Diet 2015;115:709-23. 